\title{
Solving parking issues: a case study of Abu Dhabi city
}

\author{
M. Dibas, A. Al Jassmi \& M. Ibrahim \\ Department of Transport in Abu Dhabi, UAE
}

\begin{abstract}
Abu Dhabi has grown tremendously over a brief period of time. With this rapid growth there are usually growing pains. Knowing that the city would be of significant size and densely populated the road system was constructed with high capacities. Although these considerations were made for the movement of vehicles, it seems that the storage of these same vehicles was not given the same level of consideration. The road system was designed, but early on parking requirements was not enforced.

Over the past several years, the Emirate has made attempts to correct vehicle storage or parking issues. The Department of Transport in Abu Dhabi prepared the Abu Dhabi Parking Strategy, which was comprehensive in scope as it documented current characteristics of parking from a supply/demand standpoint as well as a planning and policy standpoint (legislation and regulation). The strategy identified current and potential future issues, and provided an action plan to correct existing problems and mitigate potential negative impacts in the future.

To date, parking management system which known as MAWAQiF, has had the greatest impact on parking with broad reach of parking operations and parking enforcement.
\end{abstract}

Keywords: parking strategy, parking policies and regulations, parking management, parking issues, parking problems.

\section{Introduction}

The Emirate of Abu Dhabi has witnessed transformative growth over the past forty years, to drive forward social and economic developments including traffic growth and the issue of parking problems became a serious issue for residents 
and businesses. In 2009, the Department of Transport (DoT) published the 2030 Abu Dhabi Surface Transport Master Plan (STMP) to develop the transport aspects of Plan 2030. Effective parking management and development control formed a key part of the Congestion Management Strategy set out in the plan.

For Abu Dhabi Island, in 2009, parking and land use surveys were completed in 46 sectors predominantly in the CBD (approximately 152 sectors on Abu Dhabi Island) where parking congestion had been observed.

The parking survey indicated that in some sectors the parking demand was much higher than the available spaces for on-street parking. This formed the basis for the estimation of parking shortfalls and recommendation of actions to increase the parking supply and reduce parking demand.

Two methods were applied for the estimation of the parking demand:

\subsection{Method 1: parking survey data}

The parking surveys in the 46 sectors provided the number of parked vehicles, legal and illegal, at several times of the day. This measured and revealed the utilization of parking spaces and was considered to reflect the real demand.

\subsection{Method 2: land use based parking demand calculations}

This method used the applicable DoT parking demand rates for various land uses to estimate the parking demand. The two inputs to this method are the parking rates and the land use intensities according to the 2012 Abu Dhabi Trip Generation and Parking Rates Manual (ADTGM).

\section{Appraisal of historical problem}

A clear understanding of the historic parking supply issues and current demand for parking is an essential foundation for the Parking Strategy. This section includes an overview of the historic problems and associated impacts.

As illustrated in Figure 1 the problems stem in part from supply issues resulting from the historical plot sizes allocated to developers and in part from lack of parking management.

From the supply side, many high-rise buildings $(20+$ floors $)$ have been permitted to be constructed on plots typically measuring $24 \mathrm{~m} \times 20 \mathrm{~m}$ or less, with the following impacts:

- Basement car parks are difficult to construct due to size limitations and several floors are required to meet demand. Due to high water table levels it has been generally accepted that 2 to 3 basement levels is a reasonable provision as additional levels are too costly;

- Difficulty in providing required gradients and meeting other design criteria for vehicle circulation; and

- High capital and maintenance costs of automated parking, which has the potential to partially mitigate the problem, has been considered prohibitive. 


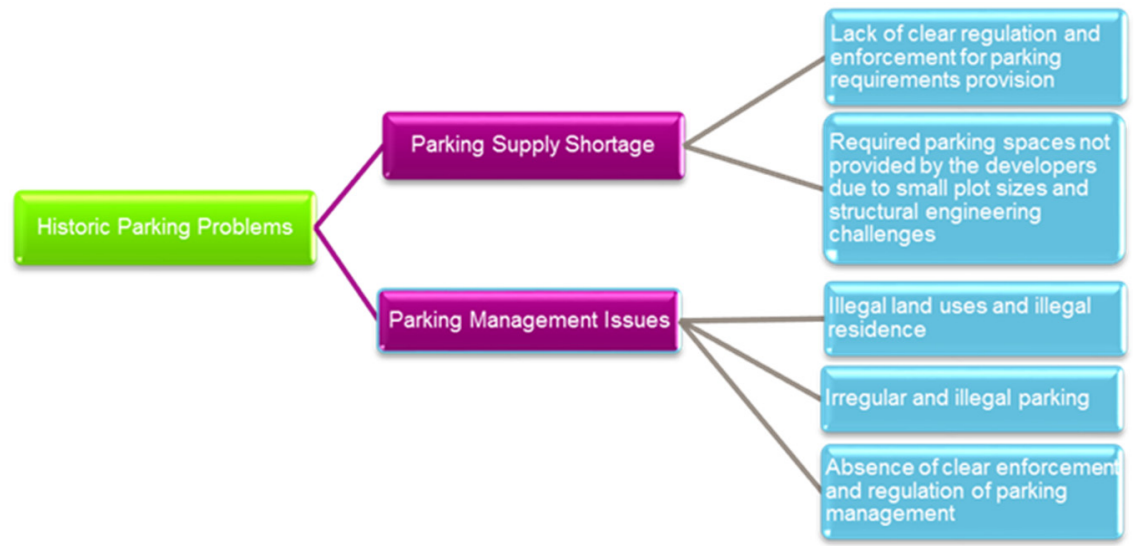

Figure 1: Historic parking problem diagram.

Therefore, significant difficulties were encountered with supplying parking underground. Moreover, the historic development code used did not allow the above ground floors to be used for parking. As a result of the above and in the absence of clear enforcement and regulation of providing parking requirements, many buildings were exempted from providing parking facilities.

In addition to this structural parking deficit there were several parking management issues that have exacerbated the parking problem including:

- Lack of adequate enforcement of land use policy often creates parking problems within Abu Dhabi. For instance, the conversion of residential towers into commercial office space without proper authorization has resulted in severe parking shortages;

- Division and sub-division of housing 'units' effectively multiplying the number of people per household;

- Certain businesses, such as rental car companies, occupy the existing surface parking lots for extended periods of time;

- Misuse of private off-street parking by private renting rather than assignment it to the building tenants. This is an indication of the propensity to unbundle parking from the rental of property. This is requires further study as part of the strategy action plans;

- Irregular on-street parking resulting from un-marked parking bays/ lots within specific sectors;

- Abandoned vehicles, (written off after accidents or whose owners have left the country), scrap and trolleys occupying or stored on marked parking areas;

- Over-concentration of land-uses within one district or sector, e.g., the private school zone and the government agencies in the civic centre, which creates a huge demand for parking facilities; and

- Land-use planning not being utilized to address problems through mixed use shared parking concepts. 
On 20 October 2009, Law No. 18 formally assigned the responsibility for parking management to the Department of Transportation. DoT had begun activities related to parking management during the first half of 2009 and established MAWAQiF as the division for the parking management program.

\section{Achievements to date}

Significant achievements have been made to manage the parking system within Abu Dhabi since 2009 after Law 18 was issued to transfer parking management to DoT. Some of the key benefits of the implementation of MAWAQiF include:

- Roll out of several sectors in Abu Dhabi with increased parking supply within some of the sectors;

- Improved access, circulation and parking layout changes;

- Better provisions of turnaround facilities for vehicles;

- Improved safety for vehicles / pedestrians;

- Improved accessibility for emergency vehicles;

- Improved pedestrian mobility, raised pedestrian crossings, traffic calming measures and handicap access and parking provisions;

- Improved ingress and egress to/from parking areas;

- Various parking restrictions applied and issuance of illegal parking violations;

- $\quad$ Disabled parking spaces are being provided as needed;

- $\quad$ Spaces for Civil Defense, Ambulance and taxis are provided;

- System is in place to handle requests from construction companies;

- Enforcement through towing and storage of abandoned vehicles is in effect;

- Inspectors are deployed to enforce regulations;

- Permits for residential and commercial uses are issued;

- Efforts made to monitor and enforce supply of parking in existing buildings; and

- Multiple convenient payment methods exist for payment of parking fees.

As of early 2014 the total number of on street surface parking bays in the Abu Dhabi Island is 102,981 spaces from 95,504 bays in 2009.

\section{Stakeholder engagement and feedback}

The key role that parking plays in the urban fabric of any city as a land use as well as part of the transport system calls for interactions with a variety of Government and private stakeholders to facilitate the development process of a Parking Strategy that will be embraced by all. As such, the Parking Strategy has been informed by an extensive programme of internal and external stakeholder engagements.

Twelve stakeholder groups were represented in the two rounds of consultation process in the development of the Parking Strategy. The stakeholder 
engagements were aimed to identify current parking problems and possible solutions and objectives to inform the development of the Parking Strategy Report. The majority of the stakeholders acknowledged that parking management - MAWAQiF, should be a component of the overall Transport Mobility Management (TMM) within a city, and more coordination between MAWAQiF, Abu Dhabi Urban Planning Council (UPC), and other public transportation elements is required. There is also a need for government-level supervision of the entire public transport system and the multi-billion dirham planned public transport investments to ensure that parking supply and other individual components are not being optimized at the expense of the overall system.

\section{Policies and regulations}

In relation to world practice benchmarking, Table 1 (source of data except Abu Dhabi: Rye [1]) represents how different cities around the world approach particular aspects of parking policies. Key aspects from the table include:

- Most cities have developed some form of on street parking regulation;

- A number of cities have developed parking standards for new buildings;

- Parking guidance systems (ITS) have recently been implemented across many European and North American cities;

Abu Dhabi is arguably catching up with the world's best practices in regards to policy and planning and the following points present a summary for each policy that will empower better managed, well enforced and effective parking strategies.

\subsection{Abu Dhabi parking law and regulations}

Parking Law 18 (2009), the umbrella parking law, empowers DoT to regulate, manage and enforce all public parking. It also provides the basis for regulating and enforcing the parking supply in new and existing developments as part of the DoT Transportation Impact Study (TIS) review and approval process. Currently DoT uses the 2012 Abu Dhabi TIS Guidelines and the 2012 Abu Dhabi Trip Generation and Parking Rates Manual (ADTGM). The stakeholder discussions rendered that Parking Law 18 provides significant improvement to parking regulation in Abu Dhabi.

\subsection{Department resolutions and policies}

Since the implementation of the DoT, there have been a number of resolutions that have been applied. Stakeholders agreed that the strategy should not exist in isolation, as a number of concerns were raised regarding the lack of connectivity between the Parking Strategy and other strategies, Abu Dhabi 2030 Vision and the Strategic Transport Master Plan. Stakeholders and committees should work in harmony to achieve the sustainability goals. Overall, the previous circulars, executive council resolutions and policies need to be combined and aligned with the Abu Dhabi 2030 vision. 
Table 1: World approach towards parking policies.

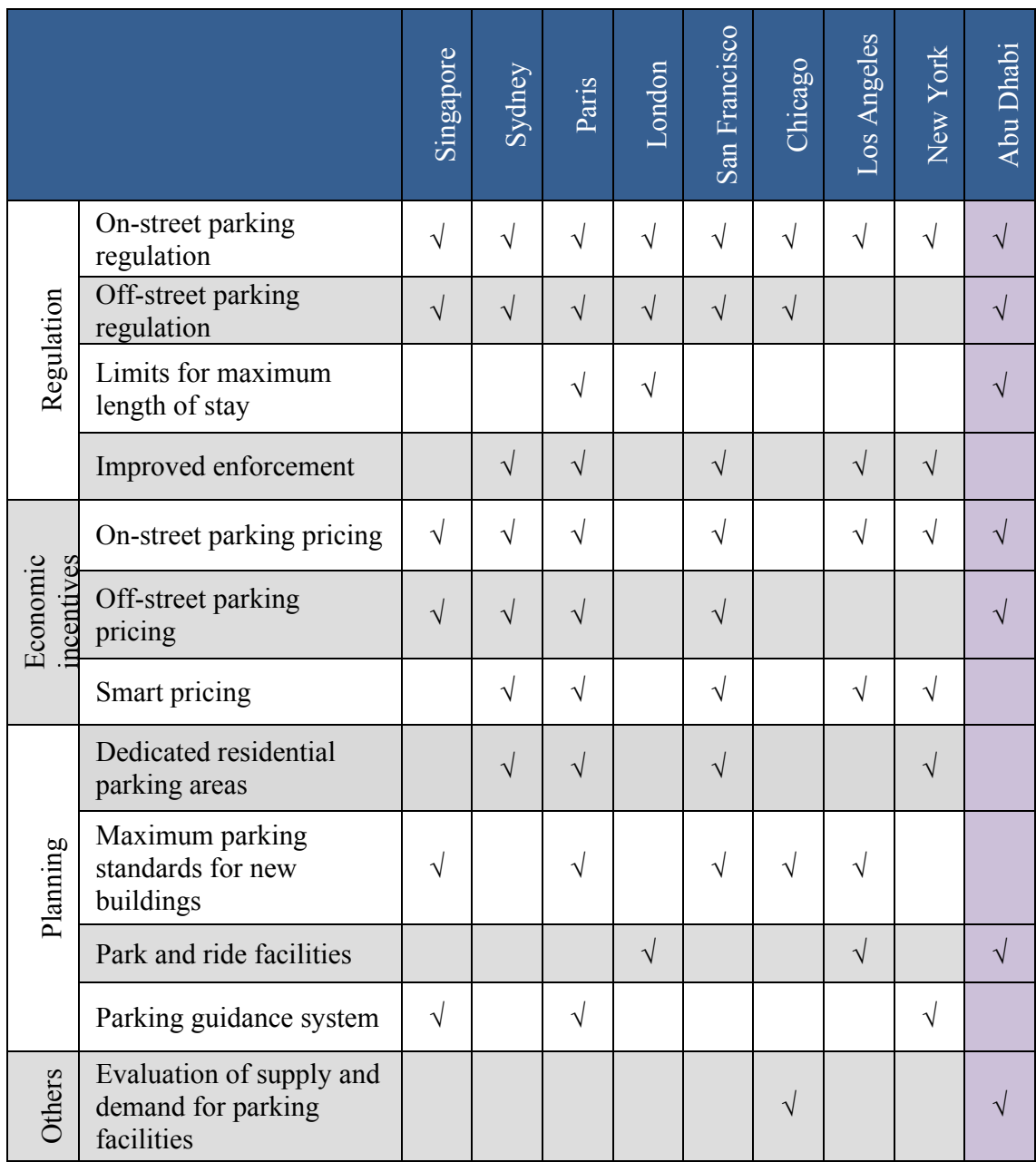

\subsection{Development right (Development Code) and future parking demand}

The Development Code has a significant impact on the parking demand and supply. The Executive Council issued a decree on approval of plots in terms of parking supply and demand setting the minimum demand to be met by the developer to be $70 \%$, however developments could be reviewed on a case-bycase basis. A study of the impact of the Development Code on parking and other sectors noted a large discrepancy between the Parking Strategy and Development Code parking demand numbers. It was agreed that regulating developments in a meticulous manner with foresight of urban growth would help alleviate parking issues. It is necessary to investigate which land uses and sectors are ideal for 
shared parking and agree upon a reduction. Further, a cap and bank system for parking regulation on new developments should be investigated in Abu Dhabi CBD.

\subsection{Permits}

Currently, MAWAQiF administers parking permits and, with the aid of SAEED, manages parking violators. On-street parking regulations specify two classifications: Standard and Premium where the rates are AED 2 and 3, respectively. The resolution defined maximum time limits for premium parking and regulated the provision of permits and reserved parking. MAWAQiF also regulates and operates public multi storey car parks (MSCP) as well as inspects public and private MSCP. MAWAQiF issues various types of permits as stipulated on the MAWAQiF website. MAWAQiF has also begun to implement an Executive Council resolution subjecting all new residential developments to fulfill at least $70 \%$ of the applicable parking rate and incur a charge of AED 50,000 for each space that is not provided (cash-in-lieu). To enforce the permit violations and other parking violations, MAWAQiF manages a tow and car pound operation. Based on the regulations in place, a fine of AED 500 for towing and a daily charge of AED 100 for storage are applied to violators. It is necessary to continue the MAWAQiF rollout, maintain the residential parking permit program and investigate the impact of price increases.

\subsection{Abandoned vehicles}

Abandoned vehicles are unsightly, take up space, and attract vandalism and crime. A strategy needs to be developed in order to remove and appropriately discard these vehicles. Currently the Abu Dhabi Municipality deals with abandoned vehicles. After a vehicle is identified as abandoned the municipality inspector monitors the vehicle for 14 days, at which point a 24 hour notice is left on the vehicle. If the vehicle is not removed, it is then towed to a storage yard. The UAE practices different means to discard including, selling of parts, auctioning the vehicle, or destroying it. Dedicated areas should be identified for storage of abandoned vehicles. Beyond that, a strategy should be developed to determine whether the vehicle is to be returned to the owner, sold in an auction, or destroyed.

\subsection{Parking space reservation policy (temporary or permanent)}

MAWAQiF is the designated authorization of parking space reservation policy. This service is provided to entities that reserve parking according to the categories defined by the scheme for banks, hotels, political and diplomatic bodies, hospitals and construction companies for projects, ministries and government departments, or any other category that may be so defined. Resident permit holders can use resident parking areas as per the timing displayed on MAWAQiF signs. This also helps residents find parking easier. Areas designated 
for residents can be easily identified through MAWAQiF signage marked with "Resident Permit Only".

\subsection{Parking rate}

Abu Dhabi Parking Strategy was based on the 2009 parking rates, which were developed from parking surveys in the year 2008. However, any new survey or assessment will be based on the Abu Dhabi Trip Generation and Parking Rates Manual (ADTGM) developed from the comprehensive parking surveys carried out in 2012. The stakeholder discussion outlined the parking requirements and rates needed to be looked at with respect to different land uses and the master plan for the area. It was considered that one flat rate could not apply everywhere and that there was a need to understand the impact of parking provision in an area and the changing land uses taking place within these areas. The key to determining applicable parking rates is to consider the governing factors such as accessibility to parking and alternative modes of travel. Also, a number of stakeholders questioned whether it was necessary for each land use in a block to have its own parking. There were suggestions that a maximum parking provision be implemented rather than the current minimum. To improve the parking rates, residential, office and retail rates should be re-evaluated. Many large global cities allow for significant reductions where justifiable and usually as a result of quality public transportation. While BRT, LRT and metro services are not currently operational in Abu Dhabi they should be considered in their development and in future parking rates.

\subsection{Car ownership}

High car ownership rates are perceived as having a significant impact on parking and congestion in Abu Dhabi. Stakeholders recognized in the discussion that ownership rates are particularly high, given a history of low public transport services, low petrol costs and a comparatively cheap cost of cars in an affluent society. It was agreed on that a high-level car ownership policy needed to restrict car ownership.

\subsection{Land use and mix}

Arguably having one of the largest impacts on parking supply and demand is the allocation of particular land uses in proximity of each other and to public transport. Currently, Abu Dhabi Island is a mix of residential, commercial, schools and retail among other land uses. Previously, there was no consideration into how land use should be planned throughout the Emirate, however, since the introduction of Abu Dhabi Urban Planning Council (UPC), the approach is more organized and well envisaged with the ability to future proof what land use should be adjacent to high quality public transport. The 2012 Parking Strategy very briefly discusses the role of land use and mix despite this being the major contributor to the parking issues experienced across the Emirate. The importance of land use mix is essential to encourage public transport use in the future 
scenario with BRT, LRT and Metro and should be examined individually for any land use plan. To improve sustainability in the Emirate and to sufficiently support the development of LRT/BRT, land uses and minimum densities should be investigated to determine appropriate developments be considered in close proximity to the public transport. Further investigate "activity areas" for shared parking and non-private car streets to encourage cycling, walking and public transport.

\subsection{Public transport impact}

Public transport is becoming an increasingly funded domain for transportation in Abu Dhabi. A key element of Parking Strategy is to allow for a smooth transition, from a car dominated society to one with a fully integrated and comprehensive public transport system. The DoT manages the comprehensive and expanding bus network connecting the Emirate, and DARB, an easy-to-use easy-to-access interactive map that provides users information on travel itinerary. The implementation of BRT, LRT and Metro remain several years away; however its continued development is essential to improve upon the sustainability of the Emirate. Public transport projects are not generally considered to directly reduce car ownership, and therefore the residential parking demand. It is accepted that high quality multi-modal public transportation will have some impact when combined with the right social and economic conditions. In addition, public transportation can have a significant impact on reducing private car trips and therefore parking requirements in non-residential land uses. Distinction between land uses is a key point to effectively utilize public transport modes.

\subsection{Transport mobility management}

The overarching transport mobility management (TMM) Strategy is composed of a number of sub-strategies that are aimed at specific target groups (workplace, education, visitor, residential). Segmentation and target group specific actions and Transport Mobility Management measures are crucial in achieving the desired outcomes. Each sub-strategy focuses on TMM plans for the relevant target groups as well as a number of stand-alone initiatives. The strategy seeks to increase choice of transportation modes and implement sustainable travel options, and is essential in helping Abu Dhabi fulfill its growth potential. Park and Ride Policy In 2011, DoT undertook a study aiming to establish "Park and Ride Services" to reduce parking demand in the CBD, to reduce congestion, to minimize environmental impacts, and to improve safety, integrity, and appeal of the municipality. Stakeholders noted the initially low uptake of Park and Ride and correlated it to the public's attitude towards public transport. The stakeholders noted that Park and Ride was an interim measure before the full public transport network was developed. However, a long term plan for Park and Ride should be produced as a supplement for the proposed Metro services. The location of park and rides should be studied to encourage the public to use the service. 


\subsection{Freight policy and regulations}

Regarding freight policy and regulations, an Emirate wide freight plan now exists, including aspirations and objectives for the treatment of road based freight activities. In most industrial areas parking controls will need to be introduced to more effectively manage the use of forecourts and road. To ensure there are adequate parking and rest stops on major roads is a key safety measure and at border crossings, where significant parking areas are needed to take into account vehicle processing delays. There are currently some formal areas for loading and unloading take place for both residential and commercial buildings. A review is necessary as adequate loading facilities are essential to good business management and for residential apartment blocks.

\subsection{School buses}

School buses are another factor considered in Parking Strategy. The majority of schools within Abu Dhabi offer a dedicated bus service for pupils at school start and finishing times but the cost is relatively high. During the school day these buses, often up to 20, require parking within school plots or on adjacent forecourts and roads. Accessibility and safety is an issue and generally parents are encouraged to pick-up and drop-off their children. During the stakeholder discussions it was determined that bus flow and parking should be separate from that of private cars. Buses owned by the school must comply with DoT parking standards and third party operators are responsible for arranging off-site parking. Physical and management safety measures need to be investigated to encourage the use of buses.

\subsection{Shared parking policy}

Implementing a shared parking policy within Abu Dhabi is one of the key aspects to reducing the parking shortfalls currently experienced, and assisting in optimizing the supply of parking in the future. A shared parking policy should include both on-street and off-street, private and public car parks. To alleviate the underutilization of parking spaces, most jurisdictions are exploring the use of shared parking as a parking management strategy. This is most successful of destinations have different peak periods or, if they share the patrons. The strategy highlights a number of ways in which parking can be shared including: shared rather than reserved parking, sharing among different land uses and implementing multi-use parking facilities. It is important to identify key areas where shared parking is feasible, to revise Law 18 to allow for developments to share parking, and to review parking supply of adjacent streets to BRT, LRT and Metro Services.

\subsection{Special category parking}

Finally, addressing special category parking (disabled, bicycle, motorcycle and valet) will improve Abu Dhabi's accessibility and promote environmentally 
friendly modes of transport to work towards the sustainability goals. Since the implementation of MAWAQiF, disabled parking bays are increasingly implemented in developments; however, they are routinely used by people who do not have a permit. It is necessary to continue adding disabled bays (with the appropriate surrounding infrastructure) and to investigate ways to enforce laws to maintain these bays for permit holders. Bicycle parking was encouraged by stakeholders as it occupies less space on the road and less space for parking. The DoT has recently released the Abu Dhabi Walking \& Cycling Master Plan, which indicates parking rates for bicycle parking. The Master Plan also identified the importance of car parking around bicycle facilities and the important role it plays with encouraging people to cycle. The reason some European countries have been able to encourage cycling as the main mode of travel is not only through the excellent facilities for the journey but also the end of trip facilities, such as showers, numerous bike racks and in prominent locations. Similar to bicycle parking and use, motorcycles are encouraged as they utilize less space on the roads and less space for parking as well, therefore potentially increasing capacity of the overall transportation network.

\section{Recommendations and key factors sustaining Abu Dhabi parking strategy}

The key factors sustaining Abu Dhabi parking strategy are:

- Objectives - Mixed objective parking strategies are sustainable and should be adopted as the basis for any review of the strategy;

- Need for Controls - Lack of parking controls is a significant cause of parking problems rather than a lack of provision;

- Live Document - The Parking Strategy needs to be seen as a live, flexible document which will need to be adaptable to emerging future needs and issues;

- Historic Deficits - Focus on addressing the historic deficits on Abu Dhabi Island in a sustainable manner with optimal provision of additional parking controls and off-street parking facilities as key actions;

- Extend Controls - Extend existing controls in the CBD and complete the introduction of paid parking in other areas.

- Industrial Areas - Development of controls for use in the industrial areas;

- New Growth Areas - Introduction of new controls in all the new, higher density growth areas.

- TMM and PT Support - The use of parking controls to support transportation mobility management (TMM) strategies and the use of PT and non-auto modes. This involves a reciprocal obligation and will only be viable when public transport proposals are implemented to deliver a network that meets the needs of a global city and which offers a viable alternative mode choice to users; 
- Differential paid parking - Need to introduce parking controls progressively, including the use of differential paid parking rates;

- Special Needs - Special access needs for vulnerable road users and road freight;

- Enforcement - Need to provide a basis for comprehensive parking enforcement within urban areas;

- Area treatments - Area based treatments and action plans should be reviewed and extended to meet emerging needs;

- Governance of strategy - Need for effective governance of the progress and performance inherent in implementing the Strategy Action Plans and continued stakeholder involvement in the successful implementation and evaluation of the Strategy;

- Improved coordination - Need to coordinate internal and external stakeholder actions

- Improved positive publicity - Creation of more positive messaging around parking enforcement and parking facilities.

The value of parking management and adequate supply of parking cannot be overstated. Research shows that over $50 \%$ of the traffic in typical downtown areas is simply on the road, cruising around the block searching for vacant, convenient parking spaces (source: Millard-Ball [2]).

Undoubtedly, the historic parking problems continue to contribute to traffic congestion with significant adverse economic and environmental implications to businesses and the general public within the Abu Dhabi Island and other centres in the emirate. In the short term, Abu Dhabi Parking Strategy seeks to continue to address the historic parking problems in the context of current and planned land use developments and public transport initiatives.

\section{References}

[1] Rye T., Parking Management: A Contribution Towards Liveable Cities, Sourcebook on Sustainable Urban Transport, Online. www.sutp.org.

[2] Millard-Ball, A., Weinberger, R. \& Hampshire, R., Is the curb $80 \%$ full or $20 \%$ empty? Assessing the impacts of San Francisco's parking pricing experiment. Transportation Research Part A: Policy and Practice, (63), pp. 76-92, 2014. 